\title{
ASTRONOMICAL GLASS PLATE NEGATIVES: MONITORING OF EMULSION LAYER DETERIORATION
}

\author{
L. MišKováa ${ }^{a}$, R. Hudec ${ }^{b}$, P. NovÁK ${ }^{c}$, M. Novotnáa,* \\ a Central laboratories, Institute of Chemical Technology in Prague \\ ${ }^{b}$ Astronomical Institute, Academy of Sciences of the Czech Republic \\ ${ }^{c}$ Department of Metal and Corrosion Engineering, Institute of Chemical Technology in Prague \\ * corresponding author: Miroslava.Novotna@vscht.cz
}

\begin{abstract}
One of the techniques for making photographic negatives most used in the history of photography were gelatin glass plates. This technique was used not only in the artistic field but also and mainly in the scientific field. The main period when glass plate negatives were used in astronomy was between 1890-1980. There are over 7 million of these negatives all over the word and they carry valuable historical scientific data. However, during the long-term storage of this material, deterioration of the emulsion (picture) layer and/or the support (glass) layer has occurred. In this paper we report on our preliminary results from an analysis of the yellowing of the emulsion layer and of gold micro-spots. Both phenomena worsen the readability of the information in the photograph, and it is necessary to prevent their formation, which is why we need to know as much as possible about their origin.
\end{abstract}

KEYWORDS: astronomical glass plate negative; deterioration; golden spots; FTIR; Raman spectroscopy; XRF; SEM/EDS; corrosion of glass.

\section{INTRODUCTION}

\subsection{BRIEF HISTORY OF PHOTOGRAPHIC NEGATIVES}

Glass has played an important part in the history of photography especially in the positive- negative process [1]. There were also techniques of preparing positives on a glass support but the process of preparing the positive on glass was very time-consuming, and the final image was also not as sharp as photographic images prepared on paper [2].

The first stable technique of preparing negatives on paper was investigated by Henry Fox Talbot in 1841. In this process the paper was waxed to obtain a transparent material for copying the image. This waxing made paper negatives unstable and that is why they were not so popular. The first glass negatives were used 6 years later by Niépce de Saint Victor. His negative system used chemicals which were almost similar to those used nowadays in negative process: halogens (KBr, KI, $\mathrm{NH}_{4} \mathrm{Br}$ a $\mathrm{NH}_{4} \mathrm{I}$ ), nitrate of silver with acetic acid and gallic acid for developing the image. The main difference was in the usage of egg albumen for the emulsion layer. The emulsion layer made by egg albumen had a disadvantage in the possibility of preparing a thicker layer on the glass, and also the time for drying and hardening of this emulsion layer was very long. That is why the egg albumen negative system was not very popular, and in 1851 egg albumen was replaced by collodion. [2]

Collodion is a solution of cellulose nitrate in ether and ethanol. The collodion system was very popular among photographers, but this process has also got some weak points. One important issue was that the whole process had to be prepared using the "wet way". That is why the equipment for this process was very complex [3]. The biggest milestone in the negative process came with the invention of R. L. Maddox, who replaced the previous substances for creating the emulsion layer by gelatine in 1871. From this time period on, photographers ceased to be chemists and they started to be artists or scientists [4].

The beginning of astronomical photography is connected with the invention of photography. The first photography of the Moon was taken in 1840 by John W. Drapper. The exposure of the image took 20 minutes. Three years later, it was also Drapper who recorded the first spectrogram of the Sun. Wider usage of photography for the scanning of the universe came with the experiments of John Herschel, so-called hypersensating. Hypersensating is a form of heat treatment: baking at $50-70{ }^{\circ} \mathrm{C}$ of the negative after application of the emulsion. This procedure brought better resolution to the photographic process.

The first milestone of scientific photography came in 1850. It was the series of the Solar eclipse by De la Rue and Pietro Secch. The scientific achievements in photography gave rise to many small associations especially at universities (e.g., Harvard). The biggest association was settled in Rochester. The George Eastman association was from the beginning specialised in selling photographic cameras, but a few years later the company varied its offer and the Kodak Eastman brand was born. The development of photographic material was not as rapid and spontaneous in the 20 th century, but it was centred in companies or in scientific institutions $[4$. 


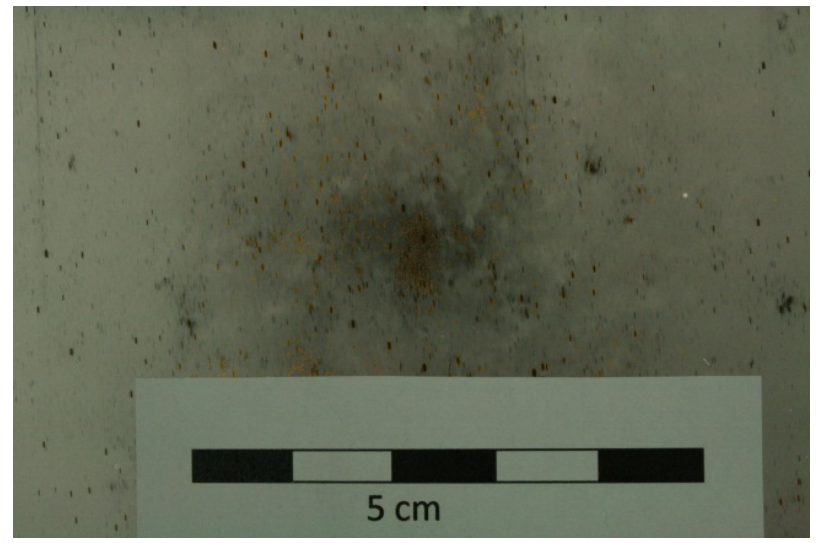

Figure 1. Photo documentation of glass plate negative with yellowing inside of the emulsion layer.

\subsection{DESCRIPTION OF "GOLDEN SPOT DISEASE"}

The first description of golden spot disease was made in 1984 [5. Sim described the formation of the microspots on the IIIa-J Kodak emulsion. In 1988 Good [6] reported about the problem of golden spot formation on the spectroscopic plates. This study reported on micro-spots that occurred not only on the IIIa-J Kodak emulsion but also on IIIa-F and IV-N emulsions which were prepared between 1978-1979, and for whose fixing was used innovative Kodak Rapid Fix. However, our recent finding is that various types gold or yellow deterioration of emulsion layer occur in numerous astronomic observatory archives.

\section{SAMPLES}

The set of about 20 tested samples consisted of glass plate negatives with a gelatine emulsion layer. The dating of the samples was between 1890 and 1980 . The samples were in their original paper or plastic packaging. The main aim of this research was to document the condition of the glass plate negatives, in order to analyse degradation products not only on the emulsion layer (which is commonly known as golden spot disease) but also on the glass support. The second aim was to suggest how to store these materials better to avoid these and other symptoms of degradation.

We documented and analysed samples of glass plate negatives from the different astronomy observatories. The photographic materials in the Astronomy is used since 1850 [7, 8, and there are millions of photographs stored in the observatories but this paper is focused onto the glass plate negatives. Attention was mainly paid to the samples of some problematic due to deterioration of the emulsion or support layer, such as glass corrosion, yellowing of emulsion or golden spot disease. The samples were from the following European astronomy observatories: OHP Haute-Provence, Sonneberg, Ondřejov and from a US observatory: USNO Washington [5]. The documentation and observation were done using photography (in the reflection and

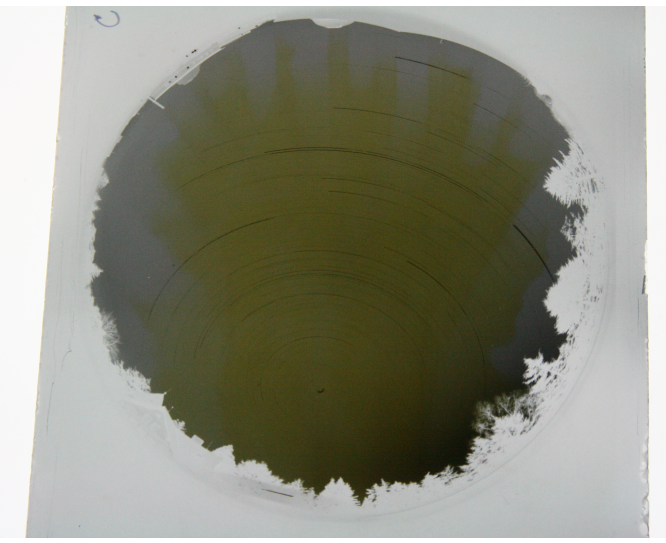

Figure 2. Detailed photographic documentation of the golden spots on the surface of the emulsion layer.

transmittance of the light) and optical microscopy. We also tried to analyse the surface signs of golden spot disease using a scanning electron microscope with energy dispersive X-Ray spectrometer (SEM/EDX) and Fourier Transform Infrared Spectroscopy (FTIR).

\section{Methodology of Glass Plate INVESTIGATION}

The first approach for the examination was optical microscopy. The observation was done using a Jenapol (Carl Zeiss, Germany) optical microscope equipped with a Jenoptic digital camera in the transmitted and reflected light.

Infrared spectra were measured using a Nicolet 6700 (ThermoScientific, USA) spectroscope with the GladiATR (PIKE, USA) single-reflectance diamond cell accessory in the spectral range of $4000-400 \mathrm{~cm}^{-1}$, spectral resolution of $4 \mathrm{~cm}^{-1}$, number of scans 128 . The background was measured relatively to the air. Special care was given to the pressure of the sample, because the main aim of the usage of this tool was to perform non-destructive analysis of the glass support and of the photo-emulsion layer.

Scanning electron microscopy was performed by TESCAN VEGA 3LMU, which is able to observe nonconductive samples in the atmosphere of low vacuum. The OXFORD Instruments INCA 350 energy dispersive spectrometer also performed a micro-analysis of the non-conductive samples. An area of $1 \mathrm{~mm}^{2}$ was chosen for the measurement of the glass side of the samples and spot analysis was chosen for the analysis emulsion layer.

\section{Results And Discussion}

As it is visible from the observation of photographs of samples, there are two main symptoms of deterioration of the emulsion layer (apart from fingerprints and silver mirroring, whose formation is well described [9], [10):

(1.) yellowing inside the emulsion layer (Fig. 1);

(2.) surface golden spot (Figs. 2 and 3 . 


\begin{tabular}{|c|c|c|c|c|c|c|c|c|c|c|c|c|c|c|}
\hline & 1 & 2 & 3 & 4 & 5 & 6 & 7 & 8 & 9 & 10 & 11 & 12 & 13 & 14 \\
\hline $\mathrm{Ag}$ & 34.15 & 30.30 & 29.89 & 30.50 & 32.19 & 30.10 & 31.70 & 32.00 & 24.63 & 25.51 & 22.75 & 19.93 & 19.18 & 19.04 \\
\hline $\mathrm{S}$ & 4.12 & 3.04 & 2.51 & 2.47 & 2.43 & 2.36 & 2.37 & 1.52 & 1.36 & 0.96 & 0.73 & 0.61 & 0.55 & 0.51 \\
\hline $\mathrm{Br}$ & 1.81 & 2.02 & 2.09 & 2.25 & 2.28 & 2.40 & 2.07 & 2.09 & 2.22 & 1.17 & 2.00 & 2.21 & 1.91 & 2.12 \\
\hline
\end{tabular}

TABLE 1. SEM/EDS element concentration [wt. \%] in each measurement spot for the sample OHP - Haute Provence.

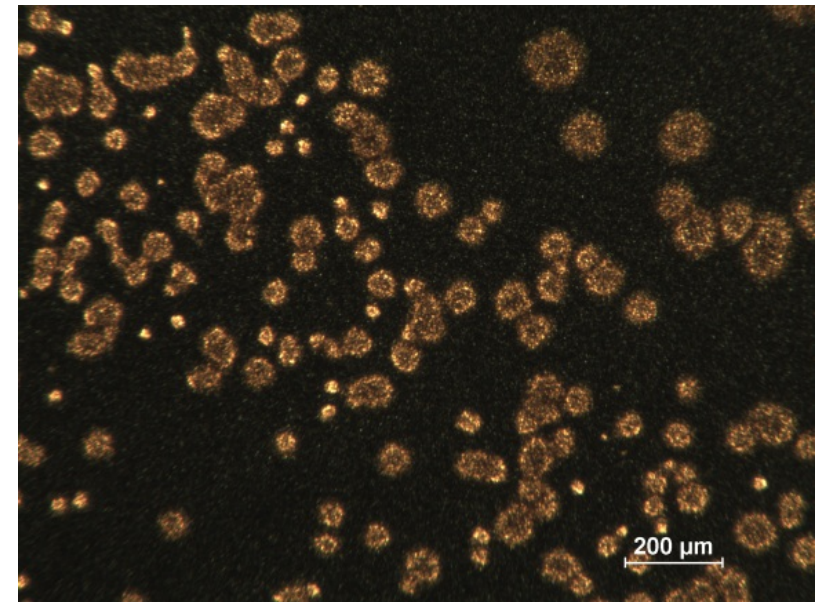

FiguRE 3. Detail of the gold spots under the optical microscope in the transmitted light.

We used two reliable analytical methods for characterization of the superficial phenomena chemical nature, namely infrared spectroscopy and scanning electron microscopy with X-Ray microanalysis. Infrared spectroscopy was chosen for the analysis of the first problem: the yellowing inside of the emulsion layer. The use of the SEM/EDS was not possible because there are no visible surface formations. Measurements were done in the area with yellow mist and in the area which seems to be without any colour changes. The emulsion layer is a typical silver gelatine one; gelatine is a protein material. That is why we can observe the main protein peaks at 1630 and $1540 \mathrm{~cm}^{-1}$, so-called amide I (vibration of $\mathrm{C}=\mathrm{O}$ group in glycoside bond) and amide II (vibration of $\mathrm{N}-\mathrm{H}$ next to the $\mathrm{C}=\mathrm{O}$ bond), the $1450 \mathrm{~cm}^{-1}$ wide peak belongs to $\mathrm{N}-\mathrm{H}$ bond bending vibration and $-\mathrm{CH}_{2}$ vibration, the double peak at $1330-1350 \mathrm{~cm}^{-1}$ is interpreted as $\mathrm{C}-\mathrm{N}$ (amide III) bond vibration, resp. $-\mathrm{CH}_{3}$ group vibration, $1230 \mathrm{~cm}^{-1}$ belong to $\mathrm{C}-\mathrm{O}$ group [13]. The main difference in the spectra (Fig. 5) of yellow and non-yellow area in the photography negative is in the peak at $1106 \mathrm{~cm}^{-1}$. This peak belongs to the sulphate $\mathrm{SO}_{4}$ group, which belongs to the stretching vibration of $\mathrm{S}-\mathrm{O}[14]$.

Golden spot disease on the surface was measured using SEM/EDS. The linear mapping measurement was chosen for the analysis of the spherical formation. The mapping line led from the centre of the golden sphere over the border of the formation (Figs. 6 and 7 ). The analysis at 14 measured spots was focused on the concentration of the sulphur and the silver elements.

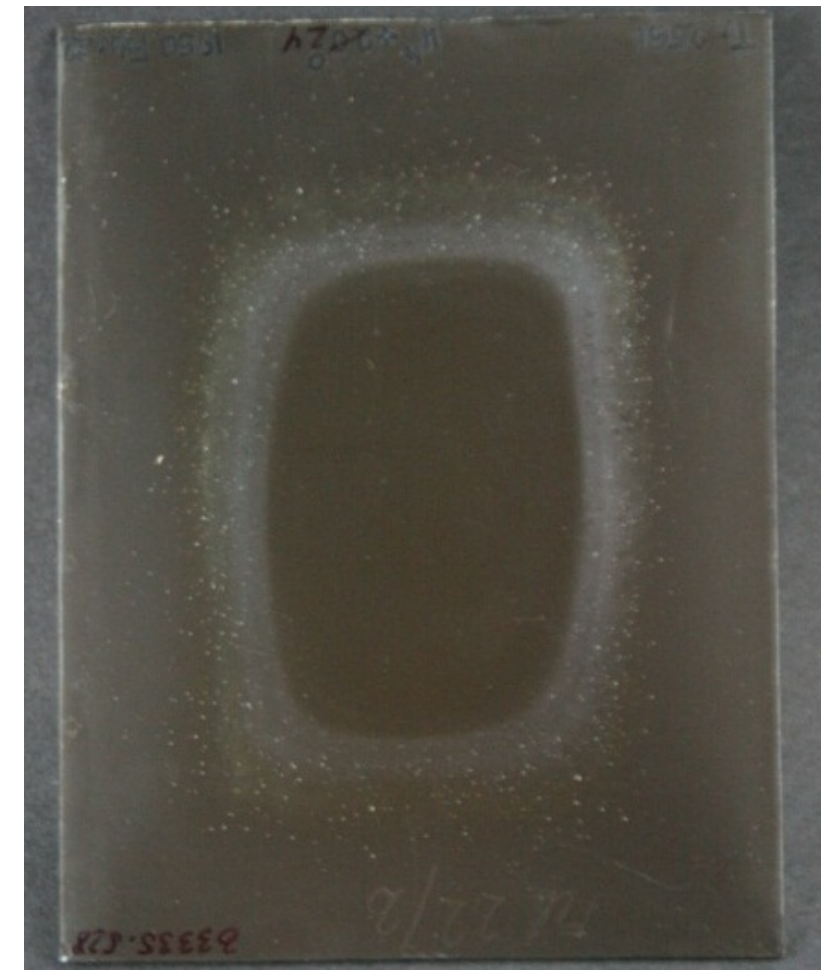

Figure 4. Photographic documentation in reflective light of another manifestation of emulsion deterioration which seems like gold micro-spots. Negative Sonneberg 3335.528.

The results showed that in the centre of the sphere there is the highest concentration of both elements. The sphere is formed around the picture of the star, thus there is the largest concentration of the silver. Remarkable is the increased concentration of the sulphur, which is going hand by hand with the silver. Decreasing concentration of both sulphur and silver is apparent at the same point (which corresponds to the thin dark ring in the SEM/EDS figure and also in the microscopic figure). After this point the concentration increased for one point to a slowly decreasing one. This pattern occurred for all golden spots and made appearance of the sphere. These results suggested that the golden spot disease in the surface of the emulsion layer is formed by silver sulphate $\left(\mathrm{Ag}_{2} \mathrm{~S}\right)$. The results also confirm the theory of golden micro-spots formation [1]. Not in the way that the golden micro-spots are formed only on the IIIa-J Kodak emulsion plates but in the case that these micro-spots are occurred in the emulsion containing bromide in the emulsion layer (see Table 1. SEM/EDS concentration of the most important element in the emulsion layer). 


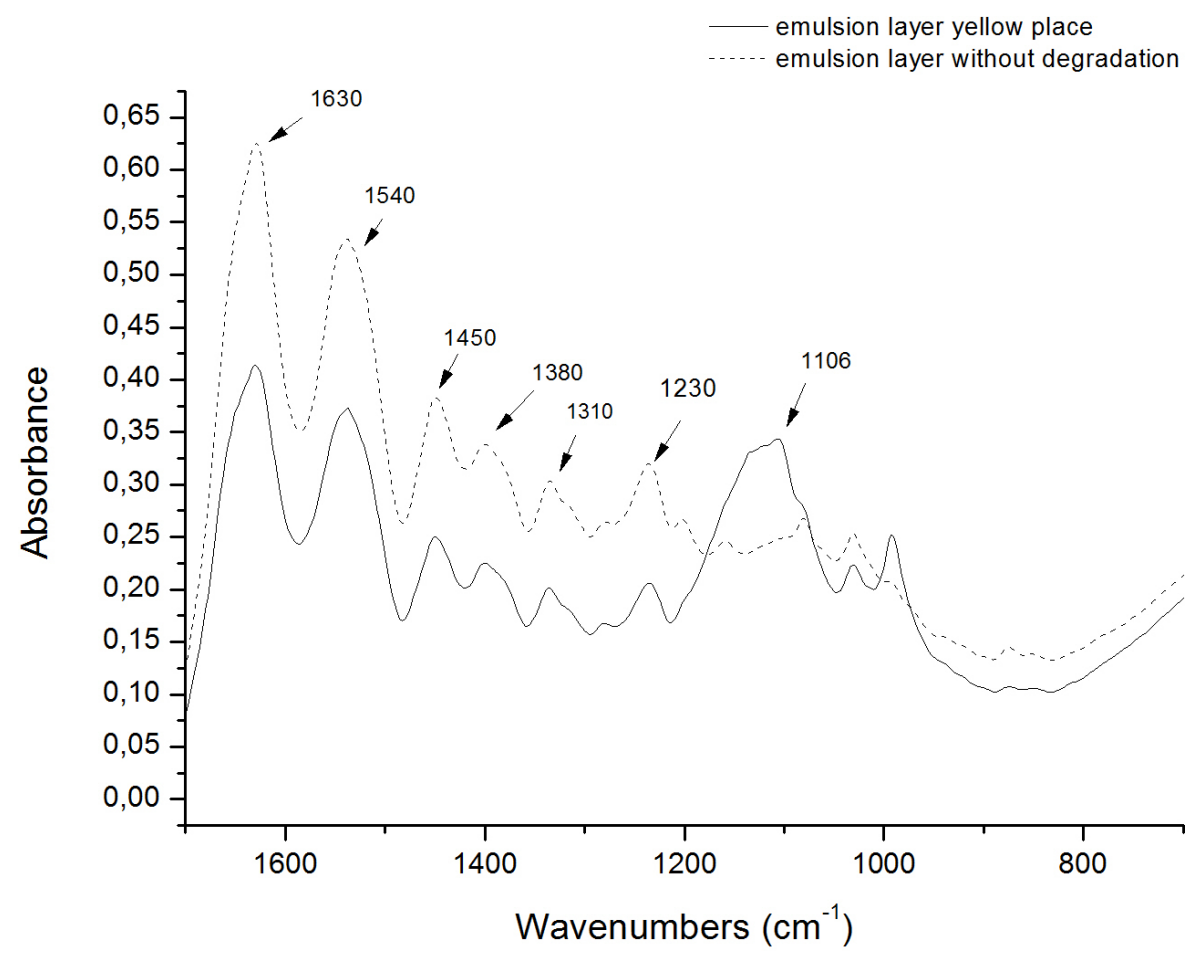

FiguRE 5. FTIR spectra of the yellow (solid line) and non-yellow part of the emulsion layer.

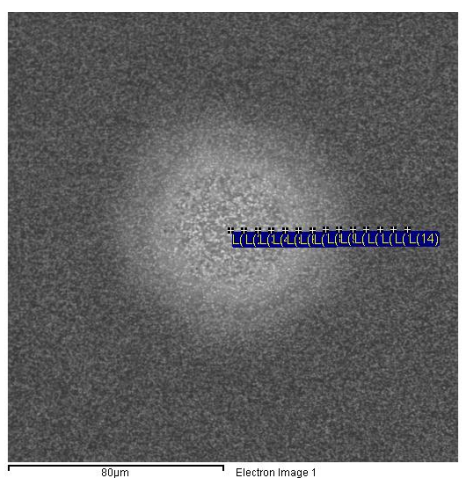

Figure 6. Line spot analysis using SEM for the glass negative from OHP-Haute Provence. At each spot the concentration of silver, sulphur and brome was measured. The concentration of these elements is given in Table 1

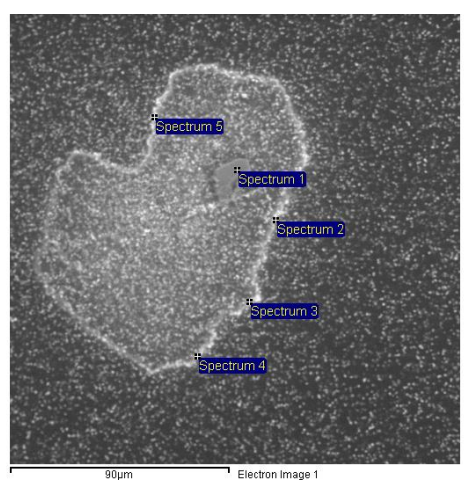

Figure 7. Detailed shape of golden shape formation on the surface of Sonneberg glass plate negative. (See Table 2 with element concentration in each point of measurement analysis).

\begin{tabular}{llrrrc}
\hline & 1 & \multicolumn{1}{c}{2} & \multicolumn{1}{c}{3} & \multicolumn{1}{c}{4} & \multicolumn{1}{c}{5} \\
\hline $\mathrm{Ag}$ & 7.16 & 28.64 & 25.76 & 25.45 & 27.51 \\
$\mathrm{~S}$ & 0.3 & 0.81 & 0.76 & 0.75 & 1.01 \\
$\mathrm{Br}$ & 1.4 & 0.07 & 0.14 & 0.16 & $*$ \\
\hline
\end{tabular}

TABLE 2. SEM/EDS element concentration [wt. \%] in each measurement spot for the Sonneberg sample.

\section{Conclusions}

We examined a set of glass plate negatives using chemico-analytical tools such as FTIR spectroscopy and SEM/EDS. We determined two types of golden deterioration of the emulsion layer during our investigation: on the surface of the emulsion layer and inside of the emulsion layer. Our preliminary results show that the golden spot disease occurs not only in the one specific type of photographic emulsion but also in various types of photography negatives products, which contain brome in the gelatine layer.

Our results suggest that the surface golden disease is caused by the secondary reaction of silver with sulphur to sliver sulphide $\left(\mathrm{Ag}_{2} \mathrm{~S}\right)$ and/or by the formation of sulphates in the emulsion layer. We identify three possible sources of sulphur:

(1.) $\mathrm{SO}_{x}$ from the atmosphere at the storage place;

(2.) sulphur contained in the packaging systems generating unsuitable microclimate for the long-term storage of the glass plates;

(3.) residual chemicals from the photographic process and their secondary reaction due to higher relative humidity and/or temperature. 
Therefore, to prevent the formation of and/or to remove the sulphur degradation products, it is necessary to monitor storage conditions, also for a better understanding of chemical reactions in the photo-emulsion layer during long-term storage under various conditions.

\section{ACKNOWLEDGEMENTS}

RH acknowledges support from GAČR grant 13-33324S.

\section{REFERENCES}

[1] Scheufler P.: Historické fotografické techniky, IPOS ARAMA Praha 1993, p.16.

[2] Burnbsng W. H.: The photohraphoc negative, New York: Scovill Manufacturing Company 1888 Burnbsng W. H.: The photohraphic negative, New York: Scovill Manufacturing Company 1888.

[3] Towler J.: Dry plate photography, London: TRUBNER \& CO. 1865, p. 39-64.

[4] Maddox R. L.: An experiment with Gelatino-Bromide, The British Journal of Photography, Vol xviii, 1871, p. 422-423 (reprinted in the 1903 issue).

[5] Miller W. C.: From the dark ages onward in Modern techniques in Astronomical Photography, European southern observatory, May 1978, p. 1-11.
[6] Sim M. E.: Microspots on IIIa-J plates ("Gold spot disease"), Astronomy with Schmidt-Type Telescopes, Astrophysical and Space Science Library 110, 1984, p. 143-145. DOI:10.1007/978-94-009-6387-0_18

[7] Good A. R.: Microspots on Spectroscopic EmulsionsAn Update. Astrophotography 1988, p. 28-33.

[8] Miller W. C.: From the dark ages onward in Modern techniques in Astronomical Photography, European southern observatory, May 1978, p. 1-11.

[9] Hoag A., Miller W.: Application of Photographic Materials In Astronomy. Applied Optics 8 (12), 1969, p. 2417-2429. DOI:10.1364/AO.8.002417

[10] Hudec R., Hudec L.: Finding hidden treasures: Investigations in US astronomical plate archives. Acta Polytechnica 53 (1), 2013, p. 23-26.

[11] EASTMAN KODAK: Conservation of Photographs. Rochester 1989, p. 71.

[12] Hendriks K. B.: Fundamentals of Photograph Conservation. A Study Guide, National Archive of Canada 1991, p. 327

[13] Stulik D., Kaplan A.: Silver Gelatine in The Atlas of Analytical Signatures of Photographic Processes, The Getty Conservation institute 2013.

[14] Nakamoto K.: Infrared and Raman Spectra of Inorganic and Coordination Compounds, John Wiley \& Sons 2008 . 